\title{
Kin structure and parallel dispersal in the black-and-gold howler monkey Alouatta caraya (Platyrrhini, Atelidae)
}

\author{
R.G. Collevatti ${ }^{1}$, A.C. Souza-Neto ${ }^{1}$, N.J. Silva-Jr. ${ }^{2}$ and M.P.C. Telles ${ }^{1}$ \\ ${ }^{1}$ Laboratório de Genética e Biodiversidade, Instituto de Ciências Biológicas, \\ Universidade Federal de Goiás, Goiânia, GO, Brasil \\ ${ }^{2}$ Systema Naturae Consultoria Ambiental Ltda., Goiânia, GO, Brasil \\ Corresponding author: R.G. Collevatti \\ E-mail: rosanegc68@hotmail.com
}

Genet. Mol. Res. 12 (4): 6018-6031 (2013)

Received April 8, 2013

Accepted October 15, 2013

Published November 27, 2013

DOI http://dx.doi.org/10.4238/2013.November.27.1

\begin{abstract}
We here investigated the kin structure and pattern of dispersal in the black-and-gold howler monkey (Alouatta caraya, Platyrrhini, Atelidae) based on genotype differences at nine microsatellite loci of 48 individuals from eight social groups along the riparian forest of the Tocantins River, Brazil. The genetic diversity $\left(H_{\mathrm{E}}=\right.$ 0.647 ) was similar to or higher than previously reported values in other Alouatta species. Given that no spatial kinship structure was detected, we found no evidence that dispersal was constrained by distance within the spatial scale analyzed $(<25 \mathrm{~km})$. Although no evidence was found for sex-biased dispersal, our results strongly suggest that extra-group copulations are common in A. caraya, and that both males and females disperse from their natal group.
\end{abstract}

Key words: Assignment test; Brazil; Cerrado; Alouatta caraya; Pedigree; Philopatry 


\section{INTRODUCTION}

Dispersal patterns can determine social organization and population structure. In most mammals, male-biased dispersal is common, particularly in Old World primates (Strier, 1999; Clarke et al., 2008). In contrast, in New World monkeys, bisexual dispersal is more common (Strier, 1999, 2011). In mammals, male-biased dispersal may be associated with polygyny and male defense of mates (Greenwood, 1980). However, in many species of New World monkeys, such as spider monkeys, muriquis, and howler monkeys, females disperse from their natal group and males act collectively in defending mates (Kowalewski and Garber, 2010; Garber and Kowalewski, 2011).

Ecological factors, such as food resources, population demography, predation, and infanticide risk, may also shape the evolution of dispersal strategy (Isbell, 2004; Lawson Handley and Perrin, 2007). Male-biased dispersal has been reported in some Atelidae genera, such as Brachyteles, Ateles, and Lagothrix (Di Fiore and Fleischer, 2005) based on behavioral observations, with bisexual dispersal reported in Alouatta (Strier, 2011). Oklander et al. (2010) observed different patterns of dispersal in black-and-gold howler monkey (Alouatta caraya) groups from continuous and fragmented forests. In Alouatta pigra, females may disperse when the social group increases in size and initiate a new group or join another group (Ostro et al., 2001). It has been argued that females in larger howler monkey groups have lower reproductive success and increased aggression (Treves, 2001). Although the age of dispersal can vary within and between species, primate species generally disperse near or just after reaching sexual maturity (Calegaro-Marques and Bicca-Marques, 1996).

Parallel dispersal has been observed in many species of New World primates, including Callitrichines and Atelines. Parallel dispersal occurs when individuals disperse together with peers or closely related individuals, or immigrate into groups containing closely related individuals (van Hooff, 2000). Although the advantages of dispersing into a group of closely related individuals might be counter-balanced by the costs of mating with close relatives, parallel dispersal may reduce these costs and increase the likelihood of successfully entering a new group (Schoof et al., 2009). Parallel dispersal has been reported in many species of Neotropical monkeys, such as the white-faced capuchin, Cebus capucinus (Jack and Fedigan, 2004a,b), the squirrel monkey, Saimiri sciureus (Mitchell, 1994), the moustached tamarin, Saguinus mystax (Garber, 1994), and the red-howler monkey, Alouatta seniculus (Pope, 2000).

Allouata. caraya (Platyrrhini, Atelidae) is a widely distributed Neotropical primate that is found from northern Argentina to central and southwestern Brazil, Paraguay, and eastern Bolivia (Hirsch et al., 2002). It is a folivore-frugivore arboreal species, and can inhabit diverse habitats, including flooded, riparian, and seasonally dry forests (Di Fiore and Campbell, 2007). A. caraya is characterized by its dichromatism, as adult males are completely black and adult females are yellowish in color (Calegaro-Marques and Bicca-Marques, 1996). Ecological studies and behavioral observations have shown that dispersal is either not sexbiased (Rumiz, 1990; Calegaro-Marques and Bicca-Marques, 1996) or may vary depending on habitat quality. For instance, habitat fragmentation may modify dispersal patterns, increasing male-biased dispersal, or limiting the ability for males and females to disperse, thereby reducing gene flow (Oklander et al., 2010).

The size of social groups of $A$. caraya is highly variable, ranging from 2 to 23 individuals (Zunino et al., 2007). Usually, the groups consist of a dominant male, several adult 
females, and immature males and females (Kowalewski et al., 1995). However, Kowalewski and Gaber (2010) reported many multi-male groups, including groups with as many as four adult males on Isla Brasileria, Argentina. In many cases, females are promiscuous (Kowalewski and Garber, 2010) and extra-group copulations have been observed (e.g. Agoramoorthy and Hsu, 2000; Fialho and Setz, 2007; Kowalewski and Garber, 2010); however, Aguiar et al. (2009) reported that such adult males were not successful in mating.

The social groups of $A$. caraya are affected by habitat quality and tend to be larger when food resources, especially fruits, are abundant (Zunino et al., 2001, 2007). It is possible that increased vigilance and defensive strength associated with multi-male howler monkey groups decreases the risk of predation and infanticide and results in increased female reproductive success (Ostro et al., 2001).

To understand the kin structure and pattern of dispersal in the black-and-gold howler monkey, A. caraya, in the riparian forest of the Tocantins River, Central Brazil, we studied the genetic structure of eight social groups using a battery of nine microsatellite markers to genotype the individuals. Our working hypothesis was that $A$. caraya presents a pattern of parallel dispersal, and that dispersal is not spatially restricted, resulting in a non-significant kin structure.

\section{MATERIAL AND METHODS}

\section{Studied area and sampling}

We studied eight social groups of $A$. caraya along the riparian forest of Tocantins River, Tocantins, TO, Brazil (Figure 1). The studied site lies $25 \mathrm{~km}$ downstream of the Tocantins River, at São Salvador do Tocantins, TO, near the confluence of the Maranhão and Paraná Rivers, in the Cerrado biome (Figure 1). The region is characterized by flat land with some rolling terrain dominated by savanna vegetation (cerrado), seasonally dry forests, and riparian forests. The region has a very long history of human disturbance, beginning in the 18 th century, and the landscape is now dominated by a mosaic of small remnants of forest of different successional stages, crops, and pasture. The riparian forest at both banks of the Tocantins River is highly fragmented (reduced in area) and disturbed, causing secondary succession (Figure 1).

A total of 48 individuals ( 27 males and 21 females) from eight social groups were captured. Infants were not sampled because manipulation could lead to mother-offspring conflict resulting in subsequent mother rejection. For sampling, the animals were immobilized with the aid of a dart gun with $9.56 \mathrm{mg} / \mathrm{kg}$ ketamine and $1.6 \mathrm{mg} / \mathrm{kg}$ xylazine anesthesia - a prescribed amount to keep the animal immobilized but conscious for 30-45 min. Based on results of previous studies, such as parasite identification and prevalence, each individual captured was measured (body size, tail size), weighed, and teeth and jaw metrics were recorded. Photographs were taken and specific characteristics were recorded (scars, pelage color, etc.) to aid in individual identification. Approximately $5 \mathrm{~mL}$ blood was drawn from the femoral blood vessel and stored in a vacutainer for DNA extraction and genetic analysis. The individuals were manipulated following the "Guide to the Capture, Handling, and Care of Mammals" from the American Society of Mammalogists, and permission for the study was granted by the Brazilian Institute for Environment/Brazilian Ministry of Environment (Ibama/MMA), according to current Brazilian laws. 


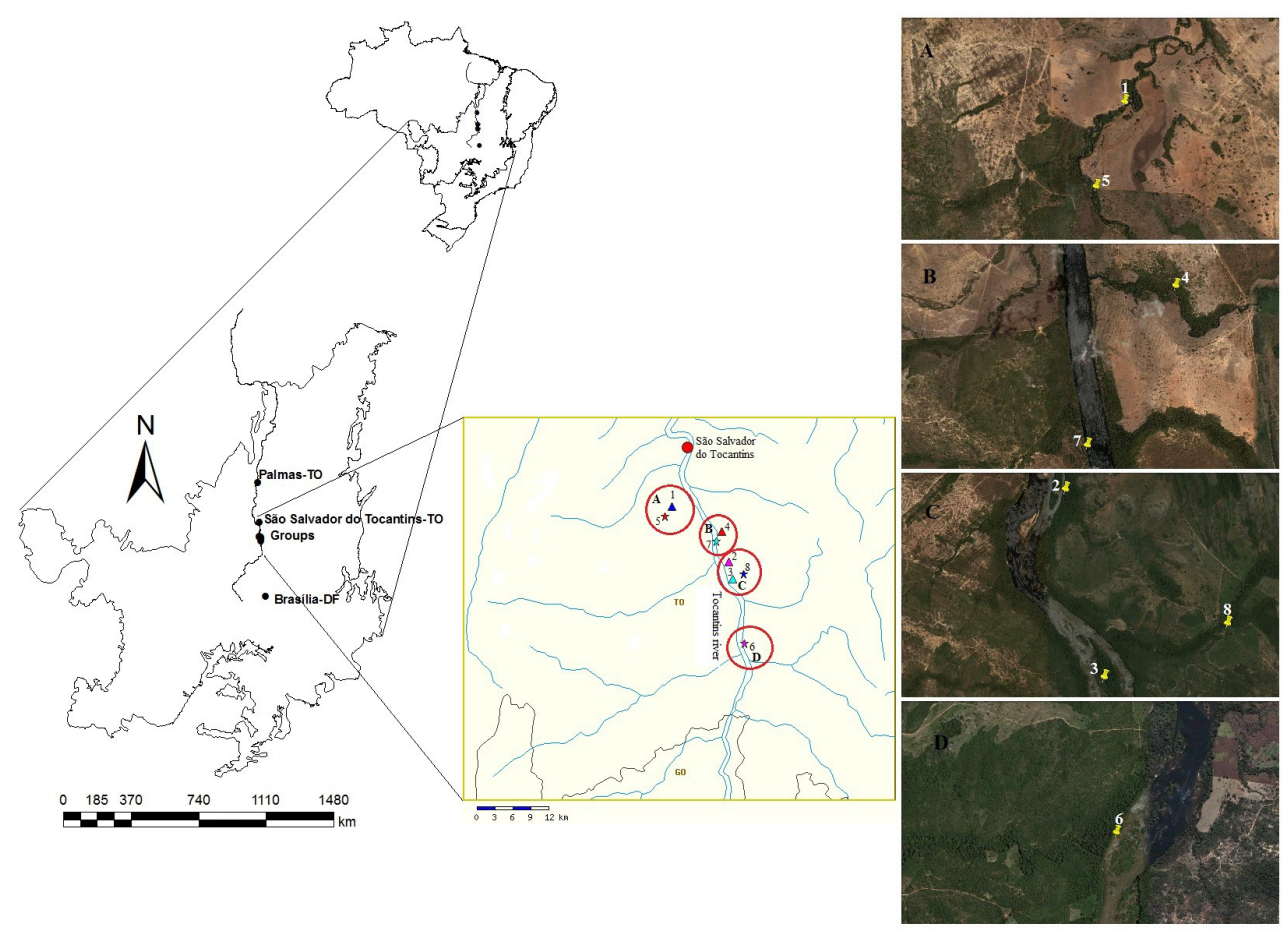

Figure 1. Sample sites of Alouatta caraya groups, along the riparian forest of the Tocantins River, TO, Brazil, depicting the riparian forest and the sample sites along the river banks (satellite images A, B, C, and D). The numbers correspond to the social group in Table 3.

Geographical coordinates of the midpoint of the groups' home ranges were obtained to calculate pairwise distances among groups.

\section{Genetic analysis}

DNA was extracted using the GFX ${ }^{\mathrm{TM}}$ Genomic Blood DNA Purification Kit (GE HealthCare), following manufacturer instructions.

Individual genotypes were determined using nine microsatellite loci that were previously developed for $A$. caraya and other primate species (Table 1). For genotyping, microsatellite amplifications were performed in a $15-\mu \mathrm{L}$ volume containing $3.96 \mu \mathrm{M}$ of each primer, $1 \mathrm{U}$ Taq DNA polymerase (Phoneutria), $200 \mu \mathrm{M}$ of each dNTP, $1 \mathrm{X}$ reaction buffer $(10 \mathrm{mM}$ Tris- $\mathrm{HCl}, \mathrm{pH} 8.3,50 \mathrm{mM} \mathrm{KCl}, 1.5 \mathrm{mM} \mathrm{MgCl}$ ), and $25 \mathrm{ng}$ template DNA. Amplifications were performed using a PE 9700 Thermal Controller (Applied Biosystems) under the following conditions: $94^{\circ} \mathrm{C}$ for $5 \mathrm{~min}(1 \mathrm{cycle}), 94^{\circ} \mathrm{C}$ for $1 \mathrm{~min}, 52$ to $68^{\circ} \mathrm{C}$ for $1 \mathrm{~min}$ (according to each locus, see Table 1$), 72^{\circ} \mathrm{C}$ for $1 \mathrm{~min}(30$ cycles $)$, and $72^{\circ} \mathrm{C}$ for $7 \mathrm{~min}(1 \mathrm{cycle})$. The amplified products were separated on $6 \%$ denaturing polyacrylamide gels stained with silver nitrate (Creste et al., 2001) and sized by comparison to a 10-bp DNA ladder standard (Invitrogen). All individuals were genotyped at least twice in independent polymerase chain reaction (PCR) amplifications and on separate polyacrylamide gels to avoid genotyping error. 


\begin{tabular}{|c|c|c|c|c|}
\hline Locus & Species & Motif & $\mathrm{Ta}\left({ }^{\circ} \mathrm{C}\right)$ & References \\
\hline Ab-07 & Alouatta belzebul & $(\mathrm{AC}) 21$ & 57 & Gonçalves et al., 2004 \\
\hline Ab-09 & Alouatta belzebul & (GAAA)18 & 58 & Gonçalves et al., 2004 \\
\hline Ab-12 & Alouatta belzebul & (GAAA) 14 & 66 & Gonçalves et al., 2004 \\
\hline Ac-14 & Alouatta caraya & (CA) 11 & 60 & Oklander et al., 2007 \\
\hline Ac-17 & Alouatta caraya & (GTTTT)17 & 66 & Oklander et al., 2007 \\
\hline Ceb-10 & Cebus capucinus & (AGAT)13 & 60 & Muniz and Vigilant, 2008 \\
\hline Ceb-128 & Cebus capucinus & (CTAT) 10 & 68 & Muniz and Vigilant, 2008 \\
\hline D5S111 & Homo sapiens & $(\mathrm{CA}) \mathrm{n}$ & 52 & Weber et al., 1990 \\
\hline D8S165 & Homo sapiens & (CA) 18 & 54 & Weber and May, 1989 \\
\hline
\end{tabular}

$\mathrm{Ta}=$ annealing temperature optimized for $A$. caraya in the present study.

\section{Microsatellite loci characterization}

Microsatellite loci were characterized for number of alleles per locus and observed $\left(H_{\mathrm{O}}\right)$ and expected $\left(H_{\mathrm{E}}\right)$ heterozygosities under the assumption of Hardy-Weinberg equilibrium. Inbreeding coefficients $(f)$, for each locus and across all loci, were also estimated (Weir and Cockerham, 1984). Analyses were performed with the FSTAT 2.9.3.2 software (Goudet, 2005) and randomization-based tests with Bonferroni's correction were carried out to determine deviations from Hardy-Weinberg equilibrium and linkage equilibrium between pairs of loci. We also estimated the probability of genetic identity (I) (Chakravart and Li, 1983), which corresponds to the probability of two random individuals displaying the same genotype, and the paternity exclusion probability $(Q)$ (Weir, 1996), which corresponds to the power with which a locus excludes a false candidate of being the father of an offspring. The combined probability of paternity exclusion, $Q C=1-\left[\Pi\left(1-Q_{\mathrm{i}}\right)\right]$, and the combined probability of genetic identity, $I C=\Pi \mathrm{x} I_{\mathrm{i}}$, were also estimated for the battery of loci.

\section{Kin structure and dispersal}

To assess the detailed kinship structure and test the hypothesis of parallel dispersal, we first estimated pairwise relatedness (Queller and Goodnight, 1989) among all individuals and within social groups using the Kinship 1.3.1 software (Goodnight and Queller, 1999). The log-likelihood ratio of the hypothesis that individuals are full-sibs $(r=0.5)$ and half-sibs $(r=0.25)$ under the hypothesis that they are unrelated $(r=0.0)$ was calculated, and a simulation (1000 pairs of individuals) was performed to determine the statistical significance of the results. We also performed simulations (1000 pairs of individuals) using the Kinship 1.3.1 software to generate the distribution of pairwise values under the hypotheses that individuals are full-sibs $(r=0.5)$, half-sibs $(r=0.25)$, first-cousins $(r=0.125)$, and second-cousins $(r=$ $0.065)$ under the null hypothesis that they are unrelated $(r=0.0)$. The simulations provided calibration for false negatives (type II error).

Next, to examine whether genotypes were spatially structured due to isolation-bydistance, we performed an autocorrelation analysis. To test for kinship structure, we estimated kinship among all adults (coancestry) based on the Nason estimator, $F_{\mathrm{ij}}$, implemented in the SPAGeDI software (Hardy and Vekemans, 2002). The $F_{\mathrm{ij}}$ values were regressed on the natural logarithm of the spatial distance between social groups. Permutation tests $(10,000$ permuta- 
tions) were performed to verify significance of kinship for each distance class and regression. Standard errors of kinship were estimated for each distance class by jackknifing over loci.

\section{Mating structure and dispersal}

We used parentage analysis (Marshall et al., 1998; Kalinowski et al., 2007) to determine mating structure and to infer dispersal patterns. The assignment test was performed using CERVUS 3.0.3 (Kalinowski et al., 2007). A simulation with 10,000 cycles was carried out, considering $80 \%$ of candidate parents sampled and $80 \%$ of loci typed, and a genotyping error of 0.01 to generate the distribution and to find critical values of $\Delta$ with $95 \%$ (strict) and $80 \%$ (relaxed) confidence. Parent pairs (sex known) were then determined with critical $\Delta=5.29$ at $95 \%$ confidence and $\Delta=1.42$ at $80 \%$ confidence.

To detect evidence of sex-biased dispersal (philopatry), an assignment test was performed, as proposed by Goudet et al. (2002), which was implemented in FSTAT 2.9.3.2 (Goudet, 2005) under the following assumptions: dispersal occurs at the juvenile stage before reproduction and individuals are sampled post-dispersal. Members of the dispersing sex may display a higher inbreeding value $(f)$ due to the Wahlund effect resulting from the mixture of individuals from different populations (Goudet et al., 2002). In addition, dispersers may have a genotype less likely to occur in its sample than average, hence, the dispersing sex tends to have lower assignment index (AIC) values (Goudet et al., 2002) than the more philopatric sex, and lower levels of differentiation, estimated by $\theta$, and relatedness. Thus, significant differences of these parameters and indices between males and females provide evidence of sex-biased dispersal. The following parameters were estimated for both sexes separately for statistical comparisons: $f$ (inbreeding coefficient) and $\theta$ (coancestry coefficient); AIc (assignment index); $v A I c$ (variance of $A I C$ ); $r$, relatedness (Queller and Goodnight, 1989). Statistical differences between the two sexes were verified using a randomization approach (10,000 randomizations) assigning a sex randomly to each multilocus genotype.

\section{RESULTS}

\section{Microsatellite loci characterization}

We found no difference in genotypes between different PCRs or polyacrylamide gels. All pairs of microsatellite loci were in linkage equilibrium (all $\mathrm{P}>0.0011$, Bonferroni's adjusted value for a nominal level of 5\%). The loci displayed high levels of polymorphism, and observed heterozygosities were not different from those expected under Hardy-Weinberg equilibrium for all loci, as well as the inbreeding coefficient over all loci (Table 2). In addition, values of the combined probability of genetic identity and of paternity exclusion (Table 2) showed that the battery of nine loci was suitable for detailed kinship analysis.

\section{Kin structure and dispersal}

We found no linear relationship between kinship and spatial distance (Figure 2) within the spatial scale analyzed $(<25 \mathrm{~km})$. Autocorrelation analysis revealed no evidence of correlation between kinship and spatial distance $(b=-0.0066, \mathrm{P}=0.439)$. 
Table 2. Characterization of the nine microsatellite loci based on 48 individuals sampled in eight social groups of Alouatta caraya along the riparian forest of Tocantins River, TO, Brazil.

\begin{tabular}{llccccc}
\hline Locus & $N_{\mathrm{A}}$ & $H_{\mathrm{O}}$ & $H_{\mathrm{E}}$ & $f$ & $Q$ & $I$ \\
\hline $\mathrm{Ab}-07$ & 4 & 0.744 & 0.623 & -0.195 & 0.331 & 0.381 \\
$\mathrm{Ab}-09$ & 4 & 0.661 & 0.663 & 0.003 & 0.402 & 0.281 \\
$\mathrm{Ab}-12$ & 6 & 0.603 & 0.796 & 0.242 & 0.482 & 0.143 \\
$\mathrm{Ac}-14$ & 5 & 0.440 & 0.698 & 0.370 & 0.36 & 0.24 \\
Ac-17 & 5 & 0.678 & 0.643 & -0.057 & 0.284 & 0.347 \\
Ceb-10 & 3 & 0.568 & 0.549 & -0.035 & 0.395 & 0.406 \\
Ceb-128 & 4 & 0.702 & 0.674 & -0.041 & 0.165 & 0.601 \\
D5S111 & 2 & 0.250 & 0.424 & 0.411 & 0.538 & 0.162 \\
D8S165 & 8 & 0.734 & 0.751 & 0.022 & $Q C=0.990104$ & $I C=1.514 \times 10^{-5}$ \\
Overall loci & 4.6 & 0.598 & 0.647 & 0.075 &
\end{tabular}

$N_{\mathrm{A}}=$ number of alleles; $H_{\mathrm{O}}=$ observed heterozigosity; $H_{\mathrm{E}}=$ expected heterozigosity; $f=$ inbreeding coefficient (all values did not differ statistically from zero, for $\mathrm{P}=0.0038$, Bonferroni's adjusted $\mathrm{P}$ value for $5 \%$ nominal level); $Q=$ probability of paternity exclusion; $Q C=$ combined probability of paternity exclusion; $I=$ probability of genetic identity; $I C=$ combined probability of genetic identity.

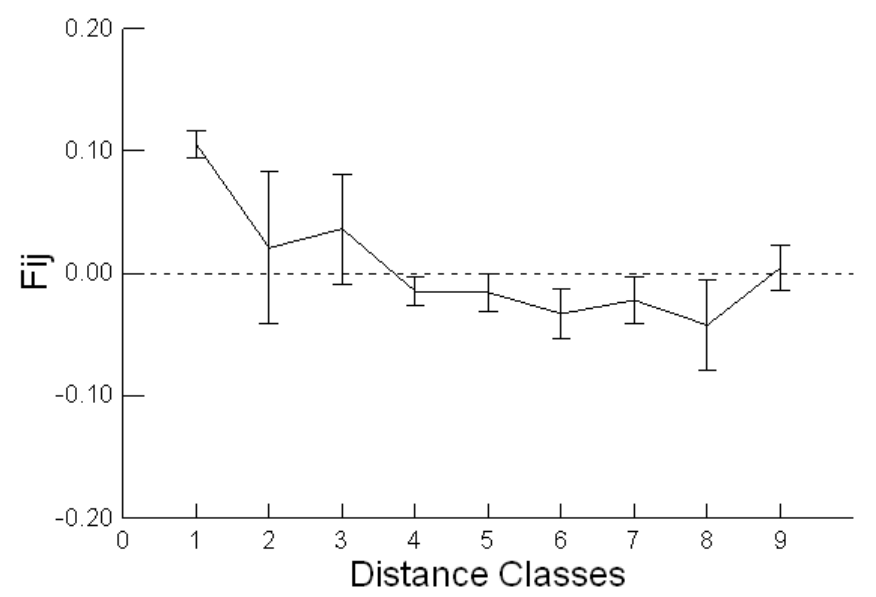

Figure 2. Relationship between kinship $\left(F_{\mathrm{ij}} \pm \mathrm{SE}\right)$ and distance based on 35 adult individuals of Alouatta caraya, from eight social groups at the riparian forest of the Tocantins River, TO, Brazil. Distance classes are: 1) intragroup, individuals from the same social group; 2) $200 \mathrm{~m}$; 3) $600 \mathrm{~m}$; 4) $6800 \mathrm{~m}$; 5) $9500 \mathrm{~m}$; 6) 12,500; 7) 15,500; 8) $16,200 \mathrm{~m}$; 9) $25,600 \mathrm{~m}$.

Inbreeding values did not differ from zero for all groups (Table 3). Overall relatedness among individuals within social groups did not differ from zero or was very small (groups 1 and 4; Table 3). A high degree of relatedness was found between individuals from the same or from different social groups. For instance, the hypothesis that the adult female Alc06 was the half-sib of Alc04, an adult male, both from social group $1(r=0.131, \mathrm{P}<0.05)$, could not be rejected, and neither could the hypothesis that the males Alc35 and Alc37 $(r=0.321, \mathrm{P}<$ 0.01 ) from social group 6 were full-sibs. The hypothesis that the female Alc06, from social group 1, was the half-sib of Alc35 and Alc39, two males from group 6, at a distance of $\sim 25$ $\mathrm{km}$ (Figure 1, see also the pedigree in Figure 3), could not be rejected $(r=0.156, \mathrm{P}<0.01 ; r=$ $0.162, \mathrm{P}<0.05$, respectively). All individuals from group 6 (five male individuals), except for two (the female and one male), were found to be highly related to the male of group 1, Alc04 (all $r>0.12$ ). Social group 8, which presented the lowest coefficients of relatedness overall, 
contained three individuals that were highly related to individuals from other social groups. The hypothesis that a male of group 8, Alc53, and a male of group 7, Alc44, were full-sibs could not be rejected $(r=0.151, \mathrm{P}<0.05)$, and we also could not reject the hypothesis that a female of group 8, Alc51, and a male of group 7, Alc45, were full-sibs $(r=0.204, \mathrm{P}<0.01)$. The hypothesis that this female of group 8, Alc51, was also a full-sib of one male of group 8 , Alc52, was also corroborated $(r=0.126, \mathrm{P}<0.01)$. The other male, Alc53, was shown to be the full-sib of a female of group 3 , Alc19 $(r=0.159, \mathrm{P}<0.05)$.

\begin{tabular}{|c|c|c|c|c|c|c|c|c|c|}
\hline \multirow[t]{2}{*}{ Group } & \multicolumn{2}{|c|}{ Males } & \multicolumn{2}{|c|}{ Females } & \multirow[t]{2}{*}{$\mathrm{N}$ total } & \multicolumn{3}{|c|}{$r(\mathrm{SD})$} & \multirow[t]{2}{*}{$f$} \\
\hline & $\overline{\mathrm{A}}$ & $\bar{J}$ & $\overline{\mathrm{A}}$ & $\bar{J}$ & & Overall & Males & Females & \\
\hline 1 & 1 & 1 & 2 & 2 & 6 & $0.180(0.151)$ & 0.471 & $0.089(0.245)$ & -0.121 \\
\hline 2 & 2 & 2 & 2 & 1 & 7 & $0.095(0.103)$ & $0.109(0.145)$ & $0.095(0.070)$ & -0.181 \\
\hline 3 & 1 & 0 & 1 & 1 & 3 & $0.058(0.090)$ & - & -0.041 & 0.000 \\
\hline 4 & 4 & 0 & 3 & 1 & 8 & $0.174(0.136)$ & $0.176(0.143)$ & $0.190(0.085)$ & -0.099 \\
\hline 5 & 2 & 0 & 3 & 0 & 5 & $0.025(0.245)$ & -0.298 & $0.001(0.198)$ & 0.091 \\
\hline 6 & 6 & 0 & 1 & 0 & 7 & $0.110(0.188)$ & $0.087(0.174)$ & & 0.065 \\
\hline 7 & 3 & 3 & 2 & 1 & 9 & $0.067(0.152)$ & $0.038(0.163)$ & $0.163(0.049)$ & -0.018 \\
\hline 8 & 1 & 1 & 1 & 0 & 3 & $0.005(0.114)$ & -0.055 & - & 0.094 \\
\hline Overall & 20 & 7 & 15 & 6 & 48 & $0.087(0.148)$ & $-0.001(0.138)$ & $-0.001(0.131)$ & 0.075 \\
\hline
\end{tabular}

$r=$ relatedness; $\mathrm{SD}=$ standard deviation of relatedness; $f=$ inbreeding coefficient. $\mathrm{A}=$ adults; $\mathrm{J}=$ juveniles.

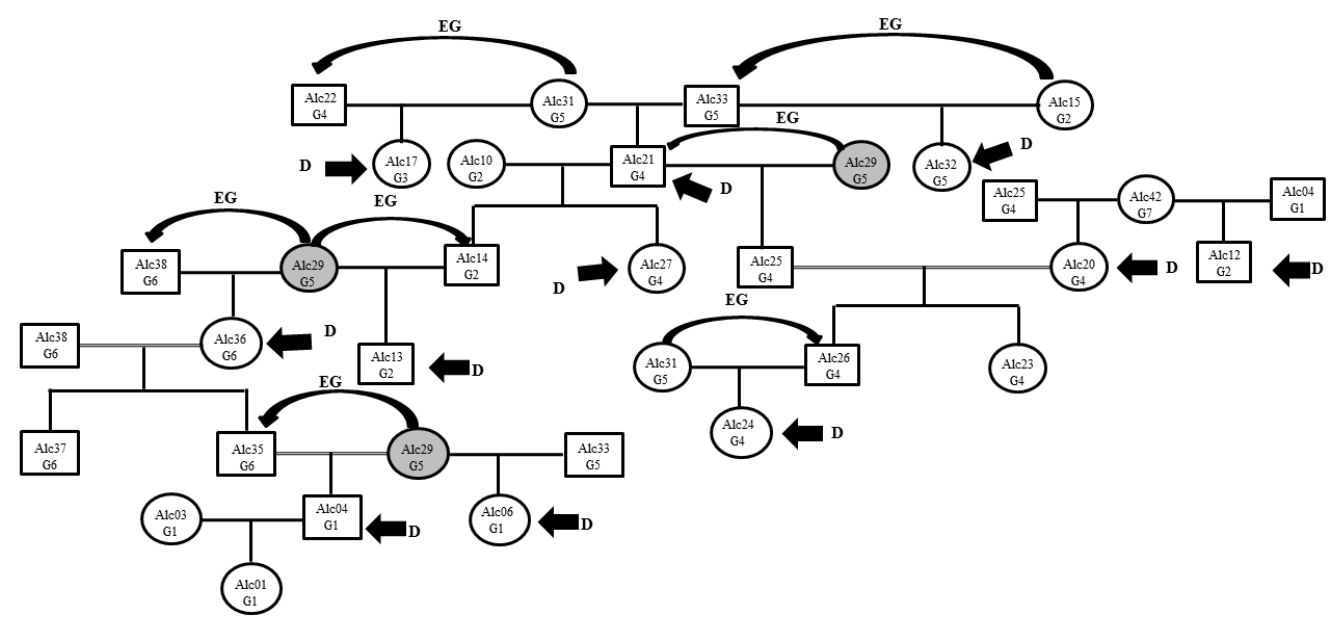

Figure 3. Pedigree of Alouatta caraya from eight social groups at the riparian forest of the Tocantins River, TO, Brazil. G1 to G7 correspond to the social groups in Table 3. Double lines indicate consanguineous mating. Arrows indicate extra-group copulation (EG) and potential dispersal from motherhood social group (D).

\section{Mating structure and dispersal}

Parentage could be assigned to 22 individuals with no mismatches. Because we sampled individuals from different generations, we could assign parentage for some of the adults (Table 4) and for six of the 12 juveniles sampled (Table 4). For all individuals but two (Alc14 
and Alc47), parental pairs were assigned at relaxed (80\%) confidence (Table 4). Only one pair of candidate parents presented $\Delta$ values higher than the critical values for all individuals. In many cases, the candidate parent pair or one of the candidate parents belonged to a different social group than that of the offspring (Table 4), suggesting frequent dispersal among social groups. For instance, candidate parent pairs for a male (Alc04) and a female (Alc06) from social group 1 were from groups 5 and 6 (Table 4 and Figure 3). The Alc04 male was assigned with $80 \%$ confidence as the offspring of the male Alc35 from group 6 and the female Alc29 from group 5, indicating successful extra-group copulation (Figure 3). This also suggests dispersal, since Alc04 was most likely born in group 5 (the social group of the female) and later dispersed to group 1 where it was found.

No significant differences between males and females were found in any of the parameters and indices analyzed in the assignment test, showing no evidence of sex-biased dispersal (Table 5).

Table 4. Parentage assignment for individuals from eight social groups of Alouatta caraya along the riparian forest of Tocantins River, TO, Brazil.

\begin{tabular}{|c|c|c|c|c|c|c|c|}
\hline Individual & Sex & Age & Group & Mother & Father & $\Delta$ & $r$ \\
\hline Alc01 & $\mathrm{F}$ & $\mathrm{J}$ & 1 & $\operatorname{Alc} 03(1)$ & Alc04 (1) & $1.48^{*}$ & $0.364 / 0.235 / 0.098$ \\
\hline $\mathrm{Alc} 04$ & M & A & 1 & Alc29 (5) & Alc35 (6) & $1.44^{*}$ & $0.189 / 0.106 / 0.242$ \\
\hline Alc06 & $\mathrm{F}$ & A & 1 & $\operatorname{Alc} 29(5)$ & $\operatorname{Alc} 33(5)$ & $1.42 *$ & $0.166 / 0.256 /-0.162$ \\
\hline Alc12 & M & $\mathrm{J}$ & 2 & $\operatorname{Alc} 42(7)$ & Alc04 (1) & $2.36^{*}$ & $0.218 / 0.126 /-0.114$ \\
\hline Alc13 & M & A & 2 & $\operatorname{Alc} 29(5)$ & Alc14 (2) & $3.10^{*}$ & $0.130 / 0.332 /-0.111$ \\
\hline Alc14 & $\mathrm{M}$ & A & 2 & Alc10 (2) & Alc21 (4) & $5.29 * *$ & $0.185 / 0.332 / 0.153$ \\
\hline Alc17 & $\mathrm{F}$ & $\mathrm{J}$ & 3 & Alc31 (5) & Alc22 (4) & $1.44^{*}$ & $0.182 / 0.199 / 0.089$ \\
\hline Alc20 & $\mathrm{F}$ & A & 4 & Alc42 (7) & $\operatorname{Alc} 25$ (4) & $1.47 *$ & $0.199 / 0.124 /-0.170$ \\
\hline Alc21 & M & A & 4 & $\operatorname{Alc} 31(5)$ & $\operatorname{Alc} 33(5)$ & $1.42 *$ & $0.318 / 0.349 / 0.124$ \\
\hline Alc23 & $\mathrm{F}$ & $\mathrm{A}$ & 4 & $\operatorname{Alc} 20(4)$ & $\operatorname{Alc} 25(4)$ & $2.66^{*}$ & $0.223 / 0.502 / 0.152$ \\
\hline Alc24 & $\mathrm{F}$ & $\mathrm{J}$ & 4 & Alc31 (5) & Alc26 (4) & $1.60^{*}$ & $0.272 / 0.337-0.079$ \\
\hline Alc25 & M & A & 4 & Alc29 (5) & Alc21 (4) & $2.56^{*}$ & $0.502 / 0.034 / 0.047$ \\
\hline Alc 26 & M & A & 4 & $\operatorname{Alc} 20(4)$ & $\operatorname{Alc} 25$ (4) & $2.64 *$ & $0.124 / 0.349 / 0.026$ \\
\hline Alc27 & $\mathrm{F}$ & $\mathrm{A}$ & 4 & Alc10 (2) & $\operatorname{Alc} 21(4)$ & $1.42 *$ & $0.205 / 0.318 /-0.142$ \\
\hline Alc32 & $\mathrm{F}$ & $\mathrm{A}$ & 5 & Alc15 (2) & Alc33 (5) & $1.48^{*}$ & $0.199 / 0.368 /-0.066$ \\
\hline Alc 35 & M & A & 6 & $\operatorname{Alc} 36(6)$ & $\operatorname{Alc} 38(6)$ & $3.53 *$ & $0.321 / 0.430 / 0.459$ \\
\hline Alc36 & $\mathrm{F}$ & $\mathrm{A}$ & 6 & $\operatorname{Alc} 29(5)$ & $\operatorname{Alc} 38(6)$ & $1.43 *$ & $0.275 / 0.321 / 0.242$ \\
\hline Alc37 & M & $\mathrm{A}$ & 6 & $\operatorname{Alc} 36(6)$ & $\operatorname{Alc} 38(6)$ & $1.65^{*}$ & $0.459 / 0.430 / 0.322$ \\
\hline Alc47 & M & $\mathrm{J}$ & 7 & $\operatorname{Alc} 46(7)$ & $\operatorname{Alc50}(7)$ & $9.98 * *$ & $0.206 / 0.309 /-0.177$ \\
\hline Alc48 & $\mathrm{F}$ & $\mathrm{J}$ & 7 & $\operatorname{Alc} 46(7)$ & $\operatorname{Alc50}(7)$ & $1.44^{*}$ & $0.124 / 0.228 /-0.177$ \\
\hline Alc49 & M & $\mathrm{A}$ & 7 & $\operatorname{Alc} 46(7)$ & $\operatorname{Alc50}(7)$ & $3.41 *$ & $0.263 / 0.106 /-0.177$ \\
\hline Alc52 & M & A & 8 & Alc46 (7) & Alc50 (7) & $1.88 *$ & $0.198 / 0.111 /-0.177$ \\
\hline
\end{tabular}

$\Delta=$ values followed by one asterisk was assigned at $80 \%$ and by two asterisks, at $95 \%$ of confidence; $r=$ relatedness between offspring and mother/offspring and father/mother and father. $\mathrm{A}=$ adults; $\mathrm{J}=$ juveniles.

Table 5. Sex-biased dispersal analysis based on 35 adult individuals of Alouatta caraya from eight social groups along the riparian forest of Tocantins River, TO, Brazil.

\begin{tabular}{lcccccccc}
\hline Sex & $\mathrm{N}$ & $f$ & $\theta$ & $r$ & $H_{\mathrm{O}}$ & $H_{\mathrm{E}}$ & AIc & $v A I c$ \\
\hline Male & 20 & -0.080 & 0.189 & 0.336 & 0.577 & 0.534 & 0.050 & 3.640 \\
Female & 15 & -0.082 & 0.111 & 0.215 & 0.606 & 0.560 & -0.040 & 0.987 \\
Total & 35 & -0.082 & 0.150 & 0.277 & 0.593 & 0.548 & - & - \\
P & & 0.373 & 0.804 & 0.763 & 0.787 & 0.678 & 0.562 & 0.064 \\
\hline
\end{tabular}

$f=$ inbreeding coefficient; $\theta=$ fixation index; $r=$ relatedness coefficient; $H_{\mathrm{O}}=$ observed heterozygosity; $H_{\mathrm{E}}=$ expected heterozygosity; $A I c=$ assignment index; $v A I c=$ variance of assignment index. 


\section{DISCUSSION}

Our results suggest parallel dispersal of related males from natal groups to form a new group or to join a previously formed group composed of unrelated individuals. Despite the low number of parent pairs and the relatively low confidence (most parent pairs were assigned at $80 \%$ confidence), the pedigree based on parentage assignment, and the coexistence of fullsibs and half-sibs, from which parent pairs were from other social groups, are consistent with a pattern of parallel dispersal. Parentage assignment may be highly affected by relatedness; e.g., paternity may not be resolved between the true father and the father's sons when males related as half-sibs to the offspring $(r \geq 0.25)$ are among the candidate males, and the mother is unknown (Marshall et al., 1998). Also, the confidence of parentage estimates is affected by the number of individuals and loci analyzed; i.e., the total number of genotypes analyzed (Marshall et al., 1998; Neff et al., 2000). Our results are certainly affected by both, resulting in the low number of candidate parent pairs assigned. Although mean relatedness among all individuals sampled was not significantly different from zero, many pairs of individuals exhibited high values of pairwise relatedness. This was most likely due to the negative pairwise relatedness between many individuals. Negative values of pairwise relatedness may occur if allele frequencies of the two compared individuals differ from the population mean in opposite directions, indicating that they are less related than the average (Queller and Goodnight, 1989).

Thus, the results of parentage assignment and kinship are consistent with a pattern of parallel dispersal. Moreover, parallel dispersal has been reported in other species of the genus Alouatta, such as red howler monkeys, A. seniculus (Pope, 2000). The coalition of related individuals for migration may provide a collective competitive advantage that exceeds individual ability in the face of aggression from unfamiliar conspecifics, and also reduces the costs of dispersal, possibly by enabling individuals to more rapidly enter a new group by strength in numbers or collective action (Schoof et al., 2009; Garber and Kowalewski, 2011).

We also observed groups comprised by related and unrelated individuals, such as group 8 . The three individuals of group 8 were most likely born in the largest groups, group 7 (see Alc52, Table 4) and group 3. The same pattern could be observed in other groups. We hypothesize that solitary males and females also disperse to initiate a new group or to join a group previously formed (see Rumiz, 1990). Considering that the infants were most likely born in the social group of the female, the pedigree analysis based on parentage assignment also suggests dispersal of solitary individuals (Figure 3).

The results of the parentage assignment test, the evidence of parallel dispersal, and the fact that groups were composed of unrelated adults that were possibly associated with lone animals dispersing, all corroborate the lack of evidence for sex-biased dispersal, and suggest a high ability of long distance dispersal in $A$. caraya. In fact, our results showed a lack of geographical kinship structure in the studied A. caraya population. Hence, dispersal is not constrained by distance, as expected under isolation-by-distance, in the spatial scale encompassed by this study $(<25 \mathrm{~km})$. In fact, we found full- and half-sibs in different social groups as far as $25 \mathrm{~km}$ apart.

Although it was previously suggested that social groups of $A$. caraya are comprised of one dominant reproductively successful adult male (Kowalewski et al., 1995; Aguiar et al., 2009, but see Kowalewski and Garber, 2010 and Garber and Kowalewski, 2011), most groups analyzed in the present study had more than one adult male, and we found evidence that more 
than one male is successfully mating in some of these groups. This may be the outcome of the highly fragmented and disturbed habitat. However, Kowalewski and Garber (2010) and Garber and Kowalewski (2011) reported stable multi-male groups of A. caraya on Isla Brasilera, which is described as a continuously flooded forest. We hypothesize that the lack of suitable habitat may decrease opportunities for dispersal and the formation of new groups, causing a biased sex ratio and mating pattern. In fact, we detected many cases of extra-group copulations (see Figure 3), which may indicate a rupture in social group structure due to a reduction in habitat quality (Zunino et al., 2001, 2007; Oklander et al., 2010). A. caraya living in fragmented forests in Argentina tend to be one male groups, whereas those in more productive and continuous forests are multi-male groups (Kowalewski and Garber, 2010). In A. pigra, which is also characterized by bisexual dispersal, females may disperse when group size increases and initiate a new group or join another smaller group (Ostro et al., 2001), possibly due to a decrease in reproductive success (Treves, 2001; Van Belle and Estrada, 2008). Oklander et al. (2010) observed different patterns of dispersal in A. caraya groups from continuous and fragmented forests, revealing male-biased dispersal in fragmented habitats. In the present study, we found that female Alc29 (Figure 3) from social group 5 was identified as the candidate mother of five siblings, and four of these were the product of extra-group copulations. Although we have other evidence for long distance dispersal, this result is most likely due to full-sib female(s) or to the mother of Alc29 that was not sampled (possible already dead), resulting in the assignment of Alc29 as the candidate mother.

The high level of fragmentation of the riparian forest of the Tocantins River has not yet affected the genetic diversity of $A$. caraya, as the studied population shows levels of genetic diversity $\left(H_{\mathrm{E}}=0.647\right)$ that are similar to or higher than values reported for other Alouatta species to date. For instance, populations of $A$. pigra from Belize presented lower heterozygosity ( 0.43 ; Winkler et al., 2004). Alouatta seniculus from Colombia also have a relatively low value of genetic diversity (0.469; Ruiz-Garcia et al., 2007a), as do populations of A. caraya from North Argentina ( 0.50; Oklander et al., 2010). Nevertheless, four species from Central and South America, A. seniculus, A. macconnelli, A. caraya, and A. palliata, presented higher values (average $\sim 0.70$, Ruiz-Garcia et al., 2007b) than were found in the present study. Although it was suggested that the southernmost species of the Alouatta genus presents higher levels of genetic diversity, with diversity declining to the north (Ellsworth and Hoelzer, 2006), results found so far show a wide variation in genetic diversity, suggesting that, in addition to the history of migration and colonization, many other factors are likely responsible for the present patterns in genetic diversity, such as the level and time since fragmentation and habitat disturbance, bottlenecks due to habitat destruction, catastrophes, and diseases (Pavelka et al., 2003; Oklander et al., 2010). The lack of a fragmentation effect, and high genetic diversity (mean $H_{\mathrm{O}}=0.65$ ) were also found for the red-handed howler (Alouatta belzebul) in populations from the low Tocantins River, eastern Amazonia (Bastos et al., 2010). An isolated population of the mantled howler monkey, A. palliata, from Barro Colorado Island also presented high levels of genetic diversity $\left(H_{\mathrm{E}}=0.584 \pm 0.063\right)$ and no effect of fragmentation (Milton et al., 2009).

In conclusion, our results showed that the mating structure of $A$. caraya is highly complex with multiple reproductively successful males in the same group, extra-group copulations, and promiscuity. Kowalewski and Garber (2010) and Garber and Kowalewski (2011) found similar results. A pattern of parallel dispersal was also supported by our data. However, the mating structure may have been affected by fragmentation, which was most likely due to 
the restriction of suitable habitat for dispersal to establish new groups, resulting in modifications in sex ratio, with multiple reproductively successful males in the same group and extragroup copulations.

\section{ACKNOWLEDGMENTS}

R.G. Collevatti and M.P.C. Telles have continuously been supported by CNPq (Brazilian Ministry of Science and Technology) grants and scholarships, whose assistance we gratefully acknowledge. We also thank an anonymous reviewer for helpful comments of the manuscript.

\section{REFERENCES}

Agoramoorthy G and Hsu MJ (2000). Extragroup copulation among wild red howler monkeys in Venezuela. Folia Primatol. 71: 147-151.

Aguiar LM, Ludwig G and Passos FC (2009). Group size and composition of black-and-gold howler monkeys (Alouatta caraya) on the Upper Parana River, Southern Brazil. Primates 50: 74-77.

Bastos HB, Goncalves EC, Ferrari SF, Silva A, et al. (2010). Genetic structure of red-handed howler monkey populations in the fragmented landscape of Eastern Brazilian Amazonia. Genet. Mol. Biol. 33: 774-780.

Calegaro-Marques C and Bicca-Marques JC (1996). Emigration in a black howling monkey group. Int. J. Primatol. 17: 229-237.

Chakravart A and Li CC (1983). The Effect of Linkage on Paternity Calculations. In: Inclusion Probabilities in Parentage Testing (Walker RH, Duquesnoy RJ, Jennings ER, Krause HD, et al., eds.). Chapter 6 (31). American Association of Blood Banks, Arlington, 411-420.

Clarke PMR, Henzi SP, Barrett L and Rendall D (2008). On the road again: competitive effects and condition-dependent dispersal in male baboons. Anim. Behav. 76: 55-63.

Creste S, Tulmann-Neto A and Figueira A (2001). Detection of single sequence repeat polymorphisms in denaturing polyacrylamide sequencing gels by silver staining. Plant. Mol. Biol. Rep. 19: 299-306.

Di Fiore A and Fleischer RC (2005). Social behavior, reproductive strategies and population genetic structure of Lagothrix poeppigii. Int. J. Primatol. 26: 1137-1173.

Di Fiore A and Campbell CJ (2007). The Atelines: Variation in Ecology, Behavior, and Social Organization. In: Primates in Perspective (Bearder SK, Campbell CJ, Fuentes A, Mackinnon KC, et al., eds.). Chapter 10. Oxford University Press, New York, 155-185.

Ellsworth JA and Hoelzer AR (2006). Genetic Evidence on the Historical Biogeography of Central American Howler Monkeys. In: Primate Biogeography: Progress and Prospects (Lehman SM and Fleagle JG, eds.). Chapter 3. Springer, New York, 81-103.

Fialho MS and Setz EZF (2007). Extragroup copulations among brown howler monkeys in southern Brazil. Neotrop. Primate 14: 28-30.

Garber P (1994). Phylogenetic approach to the study of tamarin and marmoset social systems. Am. J. Primatol. 34: 199-219.

Garber PA and Kowalewski M (2011). Collective Action and Male Affiliation in Howler Monkeys (Alouatta caraya). In: Origins of Alruism and Cooperation (Robert W, Sussman C and Robert C, eds.). Springer Publishers, New York, $145-165$.

Gonçalves EC, Silva A, Barbosa MSR and Schneider MPC (2004). Isolation and characterization of microsatellite loci in Amazonian red-handed howlers Alouatta belzebul (Primates: Plathyrrini). Mol. Ecol. Note 4: 406-408.

Goodnight KF and Queller DC (1999). Computer software for performing likelihood tests of pedigree relationship using genetic markers. Mol. Ecol. 8: 1231-1234.

Goudet J (2005). FSTAT (Version 2.9.3.2): A Program to Estimate and Test Gene Diversities and Fixation Indices. c. 2002-2005. Population Genetics Laboratory, Lausanne. Available at [http://www2.unil.ch/popgen/softwares/fstat. htm]. Accessed February 2013.

Goudet J, Perrin N and Waser P (2002). Tests for sex-biased dispersal using bi-parentally inherited genetic markers. Mol. Ecol. 11: 1103-1114.

Greenwood PJ (1980). Mating systems, philopatry and dispersal in birds and mammals. Anim. Behav. 28: 1140-1162.

Hardy OJ and Vekemans X (2002). SPAGeDi: a versatile computer program to analyse spatial genetic structure at the 
individual or population levels. Mol. Ecol. Notes 2: 618-620.

Hirsch A, Dias LG, de Oliveira-Martins L, Campos RF, et al. (2002). BDGEOPRIM, Database of geo-referenced localities of Neotropical primates. Neotrop. Primate 10: 79-84.

Isbell LA (2004). Is There no Place Like Home? Ecological Bases of Female Dispersal and Philopatry and their Consequences for the Formation of Kin Groups. In: Kinship and Behavior in Primates (Chapais B and Berman CM, eds.). Chapter 4. Oxford University Press, Oxford, 71-108.

Jack KM and Fedigan L (2004a). Male dispersal patterns in white-faced capuchins, Cebus capucinus Part 1: Patterns and causes of natal emigration. Anim. Behav. 67: 761-769.

Jack KM and Fedigan L (2004b). Male dispersal patterns in white-faced capuchins, Cebus capucinus. Part 2: Patterns and causes of secondary dispersal. Anim. Behav. 67: 771-782.

Kalinowski ST, Taper ML and Marshall TC (2007). Revising how the computer program CERVUS accommodates genotyping error increases success in paternity assignment. Mol. Ecol. 16: 1099-1106.

Kowalewski M, Bravo SP and Zunino GE (1995). Aggression between Alouatta caraya males in forest patches in Northern Argentina. Neotrop. Primate 3: 179-181.

Kowalewski MM and Garber PA (2010). Mating promiscuity and reproductive tactics in female black and gold howler monkeys (Alouatta caraya) inhabiting an island on the Parana river, Argentina. Am. J. Primatol. 72: 734-748.

Lawson Handley LJ and Perrin N (2007). Advances in our understanding of mammalian sex-biased dispersal. Mol. Ecol. 16: 1559-1578.

Marshall TC, Slate J, Kruuk LE and Pemberton JM (1998). Statistical confidence for likelihood-based paternity inference in natural populations. Mol. Ecol. 7: 639-655.

Milton K, Lozier JD and Lacey EA (2009). Genetic structure of an isolated population of mantled howler monkeys (Alouatta palliata) on Barro Colorado Island, Panama. Conserv. Genet. 10: 347-358.

Mitchell CL (1994). Migration alliances and coalitions among adult male South American squirrel monkeys (Saimiri sciureus). Behavior 130: 169-190.

Muniz L and Vigilant L (2008). Isolation and characterization of microsatellite markers in the white-faced capuchin monkey (Cebus capucinus) and cross-species amplification in other New World monkeys. Mol. Ecol. Res. 8: 402405.

Neff BD, Repka J and Gross MR (2000). Statistical confidence in parentage analysis with incomplete sampling: how many loci and offspring are needed? Mol. Ecol. 9: 529-539.

Oklander LI, Zunino GE, Di Fiore A and Corach D (2007). Isolation, characterization and evaluation of 11 autosomal STRs suitable for population studies in black and gold howler monkeys Alouatta caraya. Mol. Ecol. Notes 7: 117-120.

Oklander LI, Kowalewski MM and Corach D (2010). Genetic consequences of habitat fragmentation in black-and-gold howler (Alouatta caraya) populations from northern Argentina. Int. J. Primatol. 31: 813-832.

Ostro LET, Silver SC, Koontz FW, Horwich RH, et al. (2001). Shifts in social structure of black howler (Alouatta pigra) groups associated with natural and experimental variation in population density. Int. J. Primatol. 22: 733-748.

Pavelka MSM, Brusselers OT, Nowak D and Behie AM (2003). Population reduction and social disorganization in Alouatta pigra following a hurricane. Int. J. Primatol. 24: 1037-1055.

Pope TR (2000). The Evolution of Male Philopatry in Neotropical Monkeys. In: Primate Males: Causes and Consequences of Variation in Group Composition (Kappeler PM, ed.). Chapter 19. Cambridge University Press, Cambridge, 219-235.

Queller DC and Goodnight KF (1989). Estimating relatedness using genetic markers. Evolution 43: 258-275.

Ruiz-Garcia M, Castillo MI, Alvares D, Gardeazabal J, et al. (2007a). Estudio de 14 especies de primates platirrinos (Cebus, Saimiri, Aotus, Saguinus, Lagothrix, Alouatta y Ateles), utilizando 10 loci microsatellites: analyses de la diversidad genetica. Orinoquia 11: 19-37.

Ruiz-Garcia M, Escobar-Armel P, Alvarez D, Mudry M, et al. (2007b). Genetic variability in four Alouatta species measured by means of nine DNA microsatellite markers: genetic structure and recent bottlenecks. Folia Primatol. 78: 73-87.

Rumiz DI (1990). Alouatta caraya: population density and demography in northern Argentina. Am. J. Primatol. 21: 279-294.

Schoof VAM, Jack KM and Isbell LA (2009). What traits promote male parallel dispersal in primates? Behaviour 146: 701-726.

Strier KB (1999). Why is Female kin Bonding so Rare? Comparative Sociality of New World Primates. In: Comparative Primate Socioecology (Lee PC, ed.). Cambridge University Press, Cambridge, 300-319.

Strier KB (2011). Primate Behavioral Ecology. 4th edn. Pearson/Prentice-Hall, Cambridge.

Treves A (2001). Reproductive consequences of variation in composition of howler monkey (Alouatta ssp.) groups. Behav. Ecol. Sociobiol. 50: 61-71.

van Belle S and Estrada A (2008). Group size and composition influence male and female reproductive success in black howler monkeys (Alouatta pigra). Am. J. Primatol. 70: 613-619. 
van Hooff JARAM (2000). Relationships Among Non-Human Primate Males: A Deductive Framework. In: Primate Males: Causes and Consequences of Variation in Group Composition (Kappeler PM, ed.). Cambridge University Press, Cambridge, 183-191.

Weber JL and May PE (1989). Abundant class of human DNA polymorphisms which can be typed using the polymerase chain reaction. Am. J. Hum. Genet. 44: 388-396.

Weber JL, Kwitek AE and May PE (1990). Dinucleotide repeat polymorphisms at the D5S107, D5S108, D5S111, D5S117 and D5S118 loci. Nucleic Acids Res. 18: 4035.

Weir BS (1996). Genetic Data Analysis II. Sinauer Associates, Sunderland.

Weir BS and Cockerham CC (1984). Estimating F-statistics for the analysis of population structure. Evolution 38: 1358-1370.

Winkler LA, Zhang X, Ferrell R, Wagner R, et al. (2004). Geographic microsatellite variability in Central American howling monkeys. Int. J. Primatol. 25: 197-210.

Zunino GE, González V, Kowalewski MM and Bravo SP (2001). Alouatta caraya. Relations among habitat, density and social organization. Primates Rep. 61: 37-46.

Zunino GE, Kowalewski MM, Oklander LI and Gonzalez V (2007). Habitat fragmentation and population size of the black and gold howler monkey (Alouatta caraya) in a semideciduous forest in Northern Argentina. Am. J. Primatol. 69: 966-975. 